\title{
TÉTANO E VACINAÇÃO ANTITETÂNICA: ESTUDO NA POPULAÇÃO URBANA DE LONDRINA (PR), BRASIL *
}

\author{
José Luís da Silveira Baldy** \\ Adelino Landgraf *** \\ Antonio Carios de Queiroz*** \\ Antonio Verenhitach *** \\ Hugo Verenhitach $* * *$ \\ Agenor Mário Cattoni **** \\ Eli Villela de Magalhães *****
}

RSPU-B $/ 309$

Baldy, J. L. cia S. et al. - Tétano e vacinação antitetánica: estudo na população urbana de Londrian (PR), Brasit. Rev. Saúde públ., S. Paulo, $10: 151-66,1976$.

RESLMo: Inquérito realizado em três grupos da população urbana de Londrina (PR), representados por 602 donas-de-casa, 464 colegiais e $7 \% 8$ universitários, com o objetivo de: determinar o numero de vacinados contra o tétano; avaliar indices de conhecimento sobre o tétano, a vacina e o soro antitetanicos; correlacionar esses indices com algumas caracteristicas de cada grupo da população estudada. Concluiu-se que conceitos incorretos e carência de informação quanto ao tétano e à vacina antitetanica prevalecem na população da zona urbana de Londrina ( $P R$ ). Foi discutido o significado e a decorrencia desses fatos afmando-se que a morbiade do tétano, persistentemente elazada no Brasit, deve representar séria advertencia para as autoridades de saude publica em nosso pais, com vista à reformulação dos programas de vacinação antitetânica e à revisão dos métodos de educação sanitária adotados na divulgação dessa doença e dos recursos científicos disponiveis para sua profilaxia.

Unitermos: Tétano, Vacinação antitetanica. Soro antitetânico. População urbana, Londrina, $P R$ (Brasil).

\section{N T R O DUC Ã O}

O tétano. uma das doenças infecciosas de maior letalidade. ainda tem elevada prevalência em nosso país $2,4,10,12$. Vá- rios trabalhos $5,6,9,12,13,1+$ dão ênfase às dimensões do problema de saúde pública representado pelo tétano, entre nós.

* Trabalho realizado pelos Departamentos de Medicina Geral e Saúde Comunitária do Centro de Ciências da Saúde, de Filosofia e Estudos Sociais do Centro de Ciências Humanas e de Matemática e Estatística do Centro de Ciências Exatas e Tecnologia da Universidade Estadual de Londrina.

** Do Departamento de Medicina Geral e Saúde Comunitária da Universidade Estadual de Londrina - Rua Pernambuco, esq. Pio XII - Londrina, PR - Brasil.

* Academicos do sexto ano do curso de Medicina do Centro de Ciências da Saúde da Universidade Estadual de Londrina, PR - Brasil.

**** Do Departamento de Filosofia e Estudos Sociais do Centro de Ciencias Humanas da Universidade Estadual de Londrina, PR - Brasil.

***** Do Departamento de Matemática e Estatística do Centro de Ciências Exatas e Tecnologia da Universidade Estadual de Londrina, PR - Brasil. 
BALDY, J. L. da S. et al. - Tétano e vacinação antitetánica: estudo na população urbana de Londrina (PR), Brasil. Rev. Saúde públ., S. Paulo, 10:151-66, 1976.

Em vista de sua elevada morbidade, essa doença causa grandes despesas ao nosso governo, sendo os gastos com o tratamento incomparavelmente maiores do que os invertidos na sua prevenção. Segundo Veronesi ${ }^{14}$, a importância despendida anualmente no tratamento de tetânicos, em nosso país, seria suficiente para evitar-se, com vacinação adequada, a ocorrência de 26.000 casos da doença, com aproximadamente 13.000 mortes. A importância gasta no Hospital das Clínicas de São Paulo, segundo esse mesmo autor, correspondia em 1971 a uma vez e meia do custo da vacinação antitetânica de todas as crianças nascidas num ano, no Estado de São Paulo. 0 custo do tratamento dos casos graves de tétano - com vantagens óbvias para o prognóstico ${ }^{7}$ tem aumentado significativamente, na medida em que nos modernos hospitais esses doentes são transferidos para unidades de terapia intensiva ${ }^{\top}$ ou de respiração assistida ".

Não encontramos na literatura nenhuma referência à incidência, à mortalidade e ao gasto anual com o tétano no Estado do Paraná; somente obtivemos informação quanto à sua morbidade em Curitiba (PR), no período entre 1960 (3,3/100.000 habitantes) e $1966(2,6 /$ 100.000 habitantes), ano em que a mortalidade do tétano foi de 2,6/100.000 habitantes"

Apesar da falta de dados, parece-nos lícito admitir que a ocorrência dessa doença seja mais comum no Estado do Paraná que no Estado de São Paulo, onde está em vigência lei de vacinação com?ulsória de todos os escolares ${ }^{11,14}$, além do mais alto nível das condições sócio-econômicas da população.

No período entre $10^{\circ}$ de janeiro de 1972 e 30 de junho de 1975 , foram internados no Hospital Ĺniversitário da Universidade Estadual de Londrina (PR) 14.125 doentes, dos quais $101(0,71 \%)$ apresentavam tétano, sendo $29,7 \%$ ( 30 casos) de tétano umbilical. Cerca de três quartos dos enfermos eram moradores da zo- na rural. A letalidade registrada globalmente foi de $31,68 \%$ ( 32 casos), alcançando $9,85 \%$ ( 7 casos) entre crianças (excluídos os recém-nascidos) e adultos, e $88,33 \%$ em relação aos pacientes com tétano neonatal.

Considerando-se, pois, que o tétano ainda constitui relevante problema de saúde pública em nosso país, tivemos como objetivos neste trabalho:

1. determinar o percentual de indivíduos vacinados, na população estudada;

2. avaliar, na população estudada, alguns índices de conhecimento sobre o tétano, a vacina e o soro antitetânicos;

3. correlacionar esses indices com algumas características dos grupos estudados.

\section{POPULAÇÃO E METODOLOGIA}

O município de Londrina, situado no Norte do Estado do Paraná, apresentava em 1973, por estimativa, população de 306.232 habitantes, residindo 219.587 $(71.7 \%)$ na zona urbana e 86.645 $(28,3 \%)$ na zona rural.

Estudou-se a população da zona urbana desse município através de uma amostra composta por três grupos:

Grupo $A-602$ donas-de-casa;

Grupo $B-464$ colegiais;

Grupo $C-778$ universitários.

O levantamento foi realizado através de questionário padrão, elaborado especialmente para as entrevistas.

Foram avaliados os seguintes aspectos:

a) noção prévia da existência e da ocorrência da doença, forma de transmissão, existência de vacina, esque- 
BALDY, J. L. da S. et al. - Tétano e vacinação antitetânica: estudo na população urbana de Londrina (PR), Brasil. Rev. Saude públ., S. Paulo, 10:151-66, 1976.

ma de vacinação, eficácia, disponibilidade e custo da vacina antitetânica;

b) índice de vacinados adequadamente (três doses iniciais e reforços sucessivos a intervalos regulares), considerando-se os motivos que determinaram a vacinação e a não vacinação;

c) importância atribuída ao emprego de algumas medidas (aplicação de fumo, urina, esterco e teias de aranha em ferimentos), quanto à etiologia da doença.

\section{Grupo A: donas-de-casa}

Para a escolha das entrevistadas utilizou-se uma planta da zona urbana do município de Londrina, na qual foram listados os 1.508 quarteirões, sorteando-se então, através de uma tabela de números ao acaso ${ }^{3}, 10 \%$ desse total, ou seja, 150 quarteirões.

Estabeleceu-se previamente que a dona-de-casa a ser entrevistada seria sempre a moradora da terceira casa de cada face da rua, segundo contagem feita em sentido anti-horário. A adoção desse critério baseou-se no estudo de amostragem piloto de 20 quarteirôes, tendo-se determinado em dez o número médio de casas em cada face da rua. Quando a dona-de-casa estava ausente ou, então, negava-se a responder ao questionário, passava-se à casa imediatamente seguinte, sempre respeitando o sentido anti-horário. Quarteirões que não possuíam casas em algumas de suas faces e aqueles que possuíam somente três faces também foram incluídos no trabalho. No final, foram sorteados quarteiróes suplementares para atingir-se o número pré-estabelecido de donas-de-casa a serem entrevistadas.

\section{Grupo B: colegiais}

Dos 13 estabelecimentos de ensino de nivel colegial existentes na zona urbana de Londrina foram sorteados $50 \%$ do total, ou seja, 6 estabelecimentos. Nesses estabelecimentos de ensino colegial foram sorteados $20 \%$ das salas de aula, nos diversos períodos de atividade escolar. Entrevistaram-se todos os alunos das salas sorteadas, obtendo-se 464 questionários respondidos. Os questionários foram respondidos simultaneamente por todos os alunos, em cada período de atividade, sob a orientação e a supervisão de um dos autores deste trabalho.

\section{Grupo C: universitários}

No ano em que foi efetuado o inquérito (1974) existiam no município de Londrina três entidades de ensino de nível superior: L'niversidade Estadual de Londrina (LEL), Faculdade de Educação Física do Norte do Paraná (FEFI) e Centro de Estudos Superiores de Londrina (CESULON).

Devido à grande dispersão dos alunos da UEL por diversos Centros instalados em vários locais da cidade - já que alguns Centros da UEL ainda não tinham sido transferidos para o Campus Universitário - e pelo fato de a FEFI promover um só tipo de curso, a número reduzido de alunos, optou-se pela realizaçāo da pesquisa no CESULON.

O CESLLON mantém cursos de Ciências Sociais, Matemática, Pedagogia e Psicologia. Na época tinham sido matriculados 1.119 alunos, dos quais 778 $(69,53 \%)$ foram entrevistados.

O questionário foi respondido em todas as salas de aula, nos periodos de funcionamento da escola, sempre na presença de pelo menos um dos autores do trabalho.

\section{R E SULTADOS}

Os resultados obtidos da análise dos 1.844 questionários, respondidos pelos três grupos de população estudados. en- 
BALDY, J. L. da S. et al. - Tétano e vacinação antitetânica: estudo na população urbana de Londrina (PR), Brasil. Rev. Saude puibl., S. Paulo, 10:151-66, 1976.

contram-se nas Tabelas de 1 a 17 . Nessas Tabelas as estimativas de cada parâmetro estão apresentadas em números absolutos (n) e nas respectivas percentagens $(\%)$.

\section{COMENTARIOS}

Algumas características da população inquirida e suas concepções a respeito do tétano, do soro e da vacinação antitetânica foram colocadas em evidência pelos dados obtidos em nosso estudo. Chamaram particularmente a atenção as observações a que damos ênfase nos comentários que se seguem.

Verificamos (Tabela 1) ser muito grande, na zona urbana do município de Londrina, a percentagem de donas-de-casa analfabetas $(20,76 \%)$ ou com instrução primária incompleta $(37,36 \%)$, tendo apenas $1,51 \%$ dos participantes desse grupo realizado curso superior completo. A importância dessa característica do grupo em apreço refletiu-se na menor freqüência com que as donas-de-casa, em relação aos outros grupos, demonstraram ser dotadas de conhecimentos e concepções corretas quanto ao tétano e à vacina antitetânica, como se evidencia na seqüência destes comentários.
TABEA 1

Nivel de escolaridade do grupo A: donas-de-casa

\begin{tabular}{|c|c|c|c|}
\hline & Nivel & $\mathrm{n}$ & $\%$ \\
\hline 1. & Analfabeta & 125 & 20,76 \\
\hline 2. & Primário incompleto & 225 & 37,36 \\
\hline 3. & Primário completo & 119 & 19,77 \\
\hline 4. & Ginasial incompleto & 50 & 8,31 \\
\hline 5. & Ginasial completo & 19 & 3,16 \\
\hline 6. & Colegial incompleto & 15 & 2,49 \\
\hline 7. & Colegial completo & 31 & 5,15 \\
\hline 8. & Superior incompleto & 9 & 1,50 \\
\hline 9. & Superior completo & 9 & 1,50 \\
\hline 10. & Não responderam & 0 & 0,00 \\
\hline 11. & Total & 602 & 100,00 \\
\hline
\end{tabular}

Como decorrência dos tipos de cursos oferecidos pelo CESULON, a maior parte dos componentes do Grupo $C(87,28 \%)$ foi representada por pessoas do sexo feminino (Tabela 2), fato que admitimos não ter influído significativamente nos resultados obtidos.

Os grupos estudados não eram sem心lhantes do ponto de vista econômico ( $\mathrm{T}_{d}$ bela 3 ), verificando-se que possuíam renda familiar mensal inferior a 600 cruzeiros, $21,10 \%$ do Grupo $A, 20,91 \%$ do $B$ e $10,29 \%$ do $C$, enquanto no outio extremo (renda familiar mensal maius que 1.800 cruzeiros), as percentagens

TABEL 2

Percentagem de coleglals e universitários, quanto à distribuição por sexo

\begin{tabular}{c|cc|cc|ccc}
\hline \multirow{2}{*}{ Sexo } & \multicolumn{2}{|c|}{ Colegiais } & \multicolumn{2}{c|}{ Universitários } & \multicolumn{2}{c}{ Total geral } \\
\cline { 2 - 6 } & $\mathrm{n}$ & $\%$ & $\mathrm{n}$ & $\%$ & $\mathrm{n}$ & $\%$ \\
\hline Masculino & 255 & 54,96 & 99 & 12,72 & 354 & 28,50 \\
Feminino & 209 & 45,04 & 679 & 87,28 & 888 & 71,50 \\
\hline Total & 464 & 100,00 & 778 & 100,00 & 1.242 & 100,00 \\
\hline
\end{tabular}


BALDY, J. L. da S. et al. - Tétano e vacinação antitetânica: estudo na população urbana de Londrina (PR), Brasil Rer. Saide publ., S. Paulo, 10:151-66, 1976.

corresponderam a $25.41 \mathrm{C}$ no Grupo $A$. $31.25 r_{c}$ no $B$ e $50.90 \%$ no $C$. Sobressai desses dados a expressiva parcela da população estudada, nos três grupos. com renda familiar mensal inferior a 600 cruzeiros, sendo tamhém marcante o contraste dessa percentagem - que diminui de modo acentuado quando se comparam os Grupos $A$ e $B(21.10 \%$ e $20.91 \%$ respectivamente) e o Grupo $\left.C(10,29)_{0}\right)$. Chama também a atenção a alta percentagem de universitários cuja renda familiar mensal ultrapassava 1.800 cruzeiros, quando cotejada com a dos Grupos $A$ e $B$.

Observa-se que o tétano é uma infecção cuja existência é muito divulgada em nosso meio: quase a totalidade dos entrevistados, nos três grupos, tinham conhecimento prévio da doença (Tabela 4), o mesmo ocorrendo quanto à sua forma de transmisão (Tabela 5 ).

Mais de $69 \%$ da população entrevistada admitiu que o tétano é doença curável (Tabela 6 ). enquanto apenas um quarto das donas-de-casa e quase $50 \%$ dos colegiais e universitários admitiram que determina morte com pequena freqüência (Tabela 7 ).

Dos dados acima referidos pode-se depreender que - apesar de ser doença muito conhecida - o tétano não é considerado. de modo geral. moléstia de prognóstico grave. concepção que se contrapõe frontalmente ao fato ainda hoje registrado na prática médica: à semelhança do que se verifica em vários centros do nosso país ${ }^{4}, 5,10,12,14$, a letalida. de do tétano no Hospital Ĺniversitário de Londrina - conforme já referimos - $\dot{\hat{t}}$ de $31.68 \%$.

É de causar perplexidade o elevado ín dice $(26,75 \%)$ de donas-de-casa da zo. na urbana de Londrina que ignoravam a existencia de vacina antitetânica (Tahela 8). Por sua vez. alta percentagem de indivíduos dos três grupos admitiu erroneamente ser dotada a vacina anti- tetânica de propriedade curativa quando empregada no tratamento do tétano (Tabela 9).

Desconheciam a finalidade com que é utilizada a vacina antitetânica, $30.23 \%$ das donas-de-casa. $12.07 \%$ dos colegiais e $3.17 \%$ dos universitários (Tabela 10 ), percentagens a nosso ver muito elevadas, particularmente para o primeiro e o terceiro grupo; parece-nos preocupante que quase um terço de mães de família residentes na zona urbana de uma cidade com as características de Londrina desconheçam para que serve a vacina antitetânica. Também nos parece inadmissível que sequer um estudante de nível universitário possa ignorar esse fato.

Considerando-se a simplicidade e a inocuidade da racinação e a fácil disponibilidade e o baixo custo da racina antitetânica em nosso meio. foi muito haixo o indice de indivíduos que se consideravam racinados contra o tétano: apenas $18.11 \%^{\circ} \mathrm{C}$ no Grupo $A, 43.97 \%$ no $B$ e $33.16 \%$ no $C$ (Tabela 11). Essas cifras. acrescendo-se ao fato de serem baixas de per si, devem ainda ser consideradas com reservas, uma rez que como se pode deduzir das informações abaixo relacionadas - muitos desses indivíduos não faziam distinção entre soro e racina antitetânicos e. se foram vacinados. muitos deles não devem ter recebido o número mínimo de doses imunizantes e reforços com intervalos adequados.

Entre os individuos que se consideravam racinados. a ocorrência de ferimentos constituiu-se em fator que. com muita freqüência. condicionou a vacinação. tal como a entendiam os entrevistados (Tabela 12 ), alcançando $55.96 \%$ no Grupo $A \cdot 15.38 \%$ no $B$ e $18.99 \%$ no $C$.

Aliás. grande parcela dos entrevistados consideravam erroneamente que a vacina de ieria ser aplicada apenas na oportunidade em que ocorresse um ferimento, correspondendo esse ponto de vista à ele- 
BALDY, J. L. da S. et al. - Tétano e vacinação antitetânica: estudo na população urbana de Londrina (PR), Brasil. Rev. Saúde públ., S. Paulo, 10:151-66, 1976.

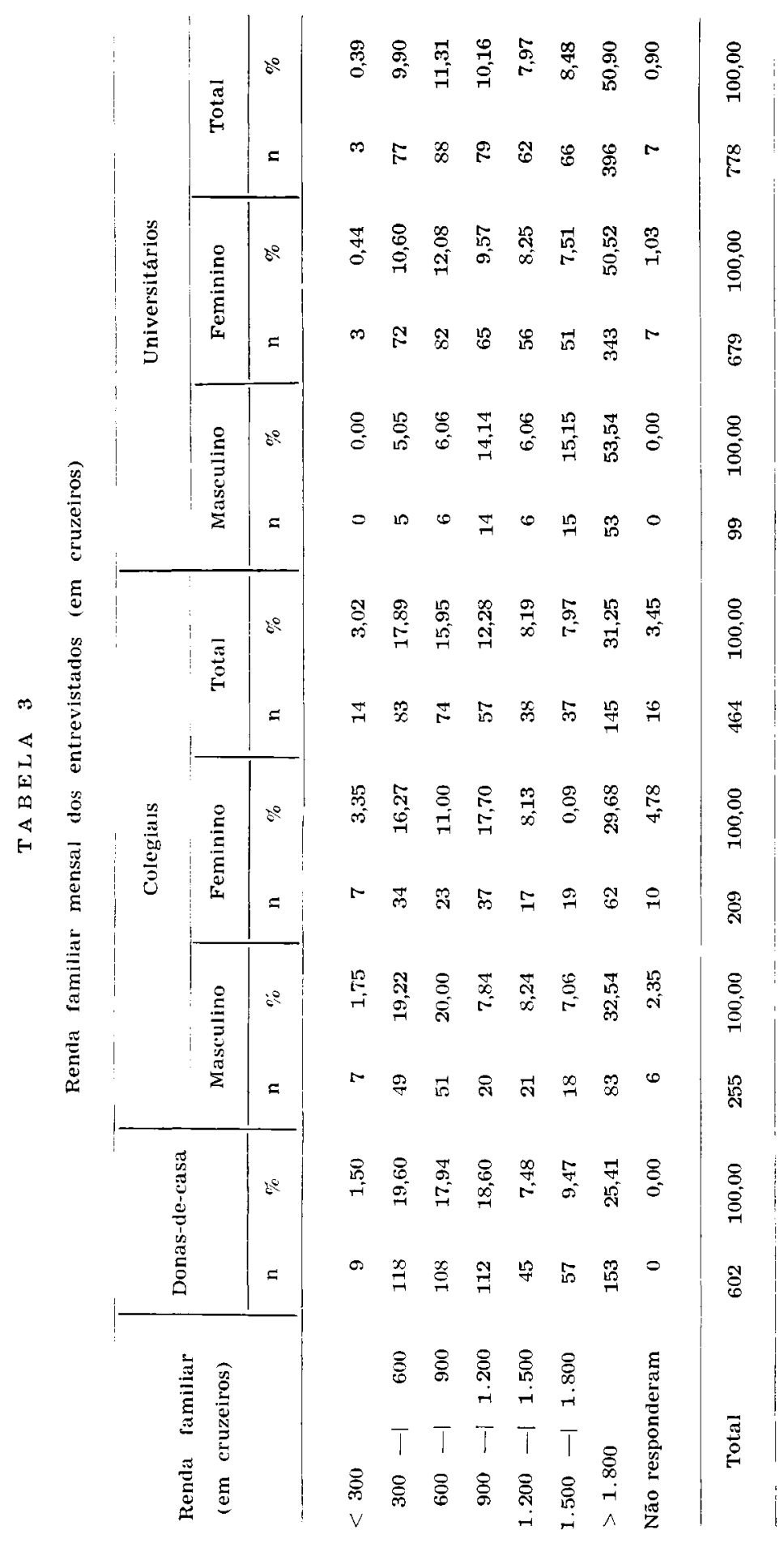


BALDY, J. L. da S. et al. - Tétano e vacinação antitetânica: estudo na população urbana de Londrina (PR), Brastl. Rev. Saúde públ., S. Paulo, 10:151-66, 1976.

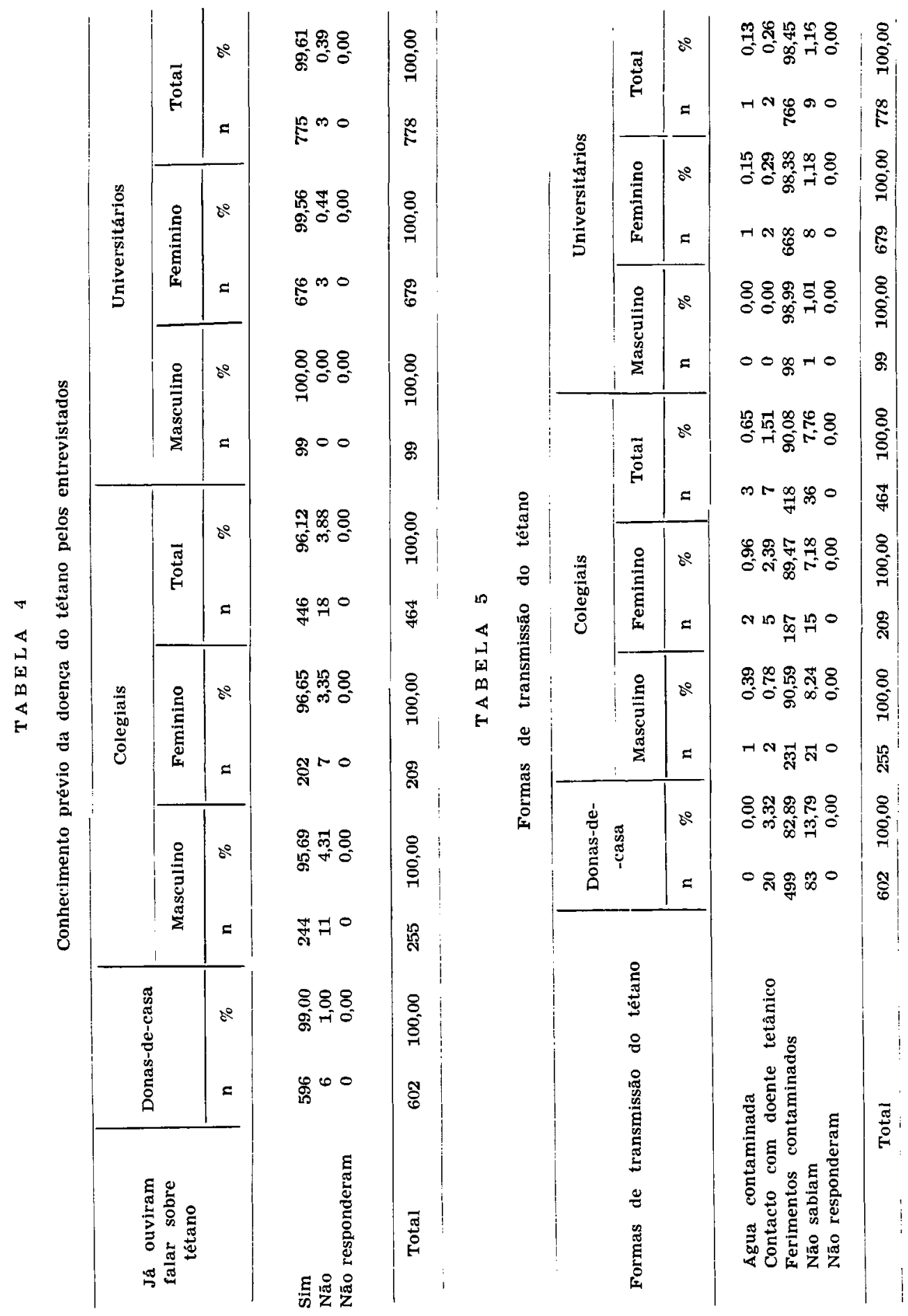




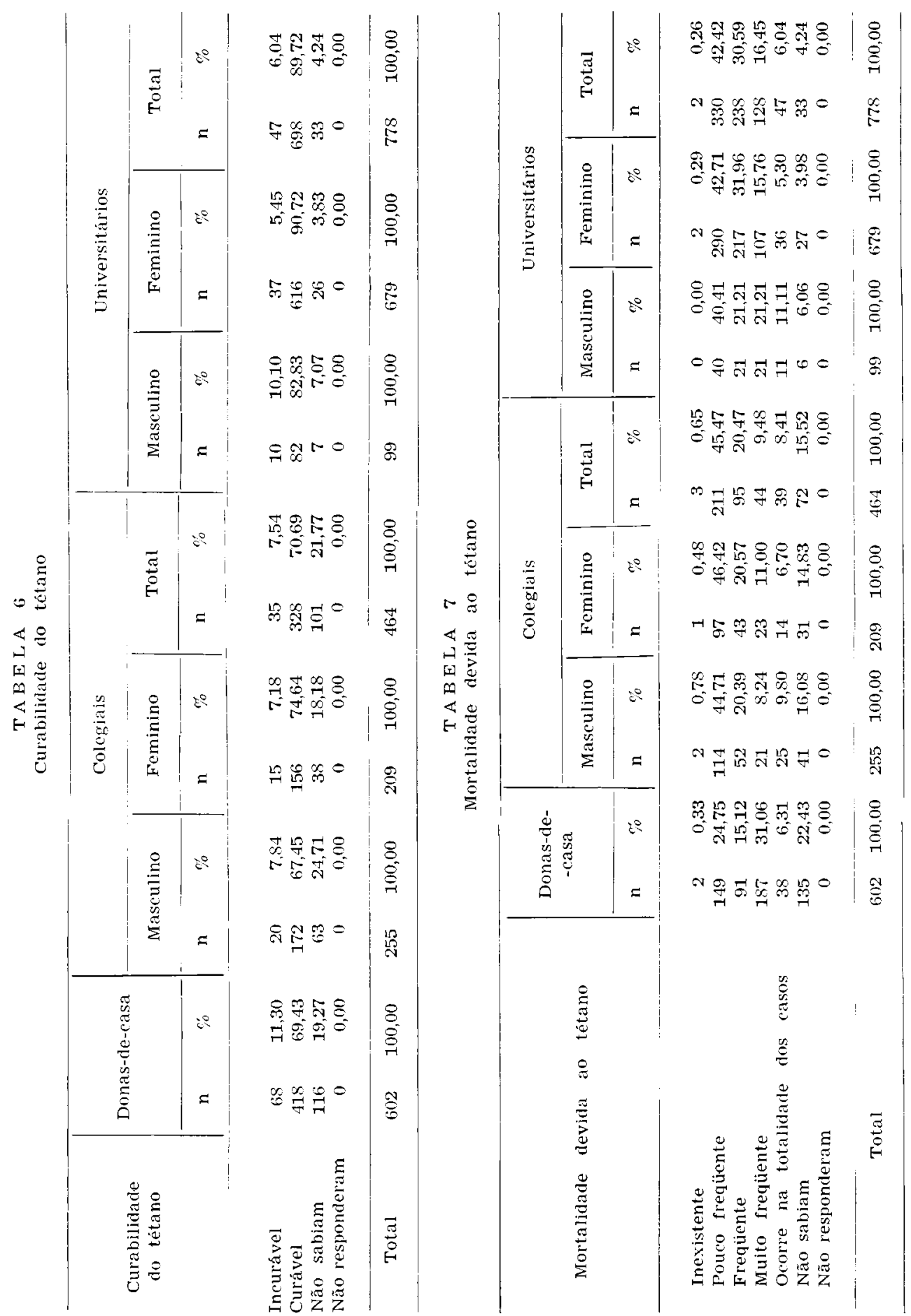




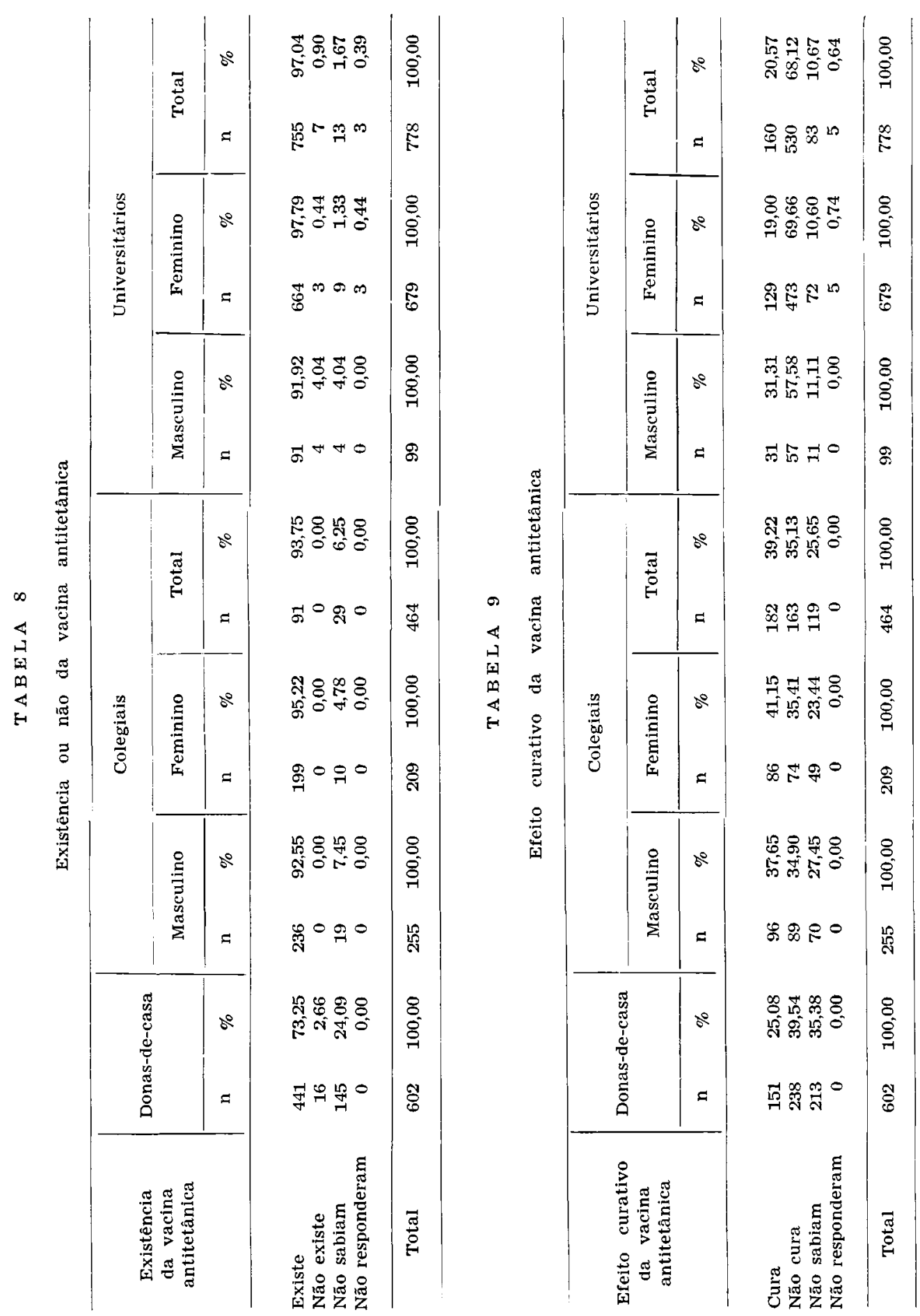


BALDY, J. L. da S. et al. - Tétano e vacinação antitetânıca: estudo na populaçāo urbana de Londrina (PR), Brasil. Rer. Saúde pübl., S. Paulo, 10:151-66, 1976.

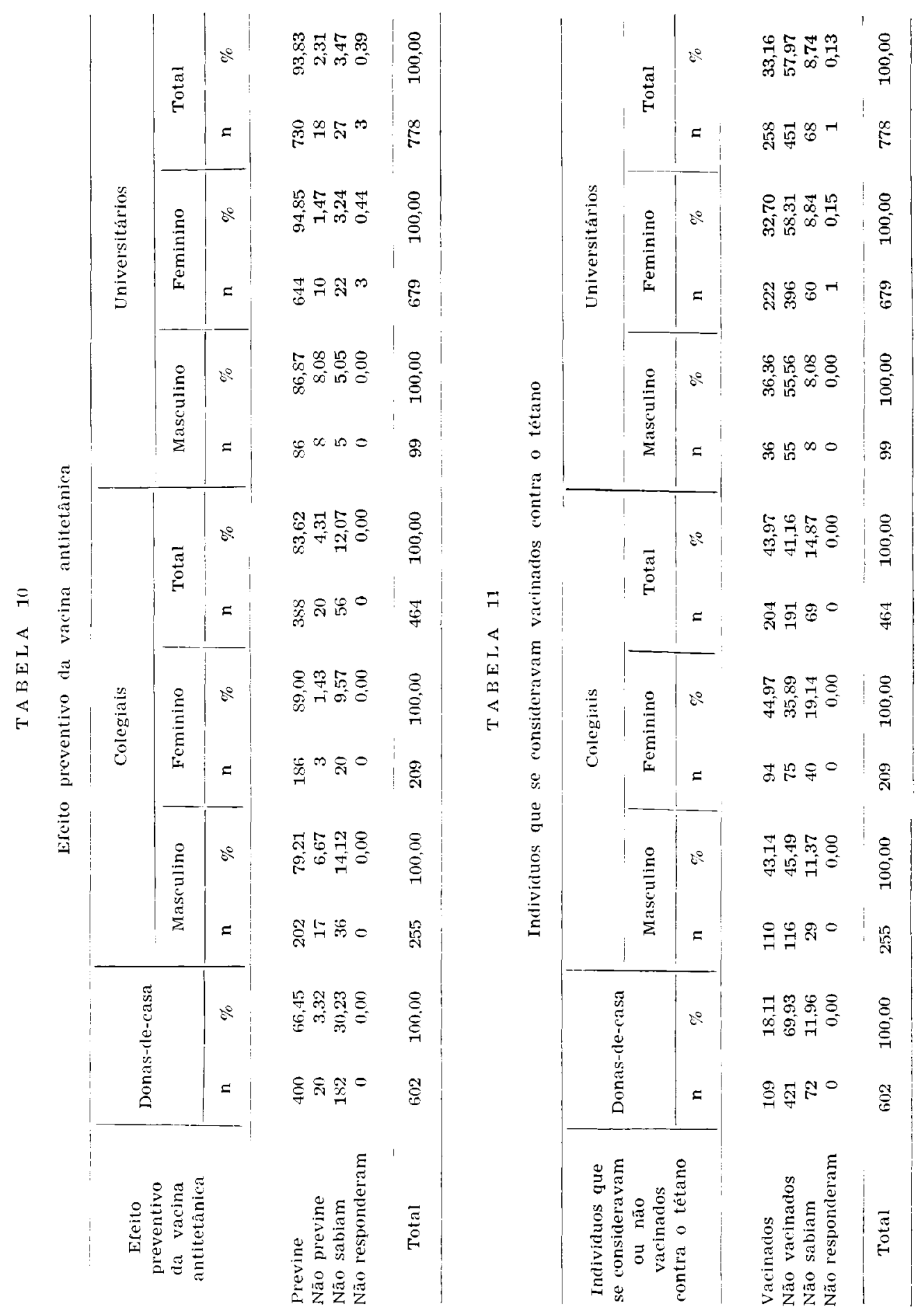


BALDY, J. L, da S. et al. - Tétano e vacinação antitetânica: estudo na população urbara de Londrina (PR), Brasil. Rev. Saúde públ., S. Paulo, 10:151-66, 1976.

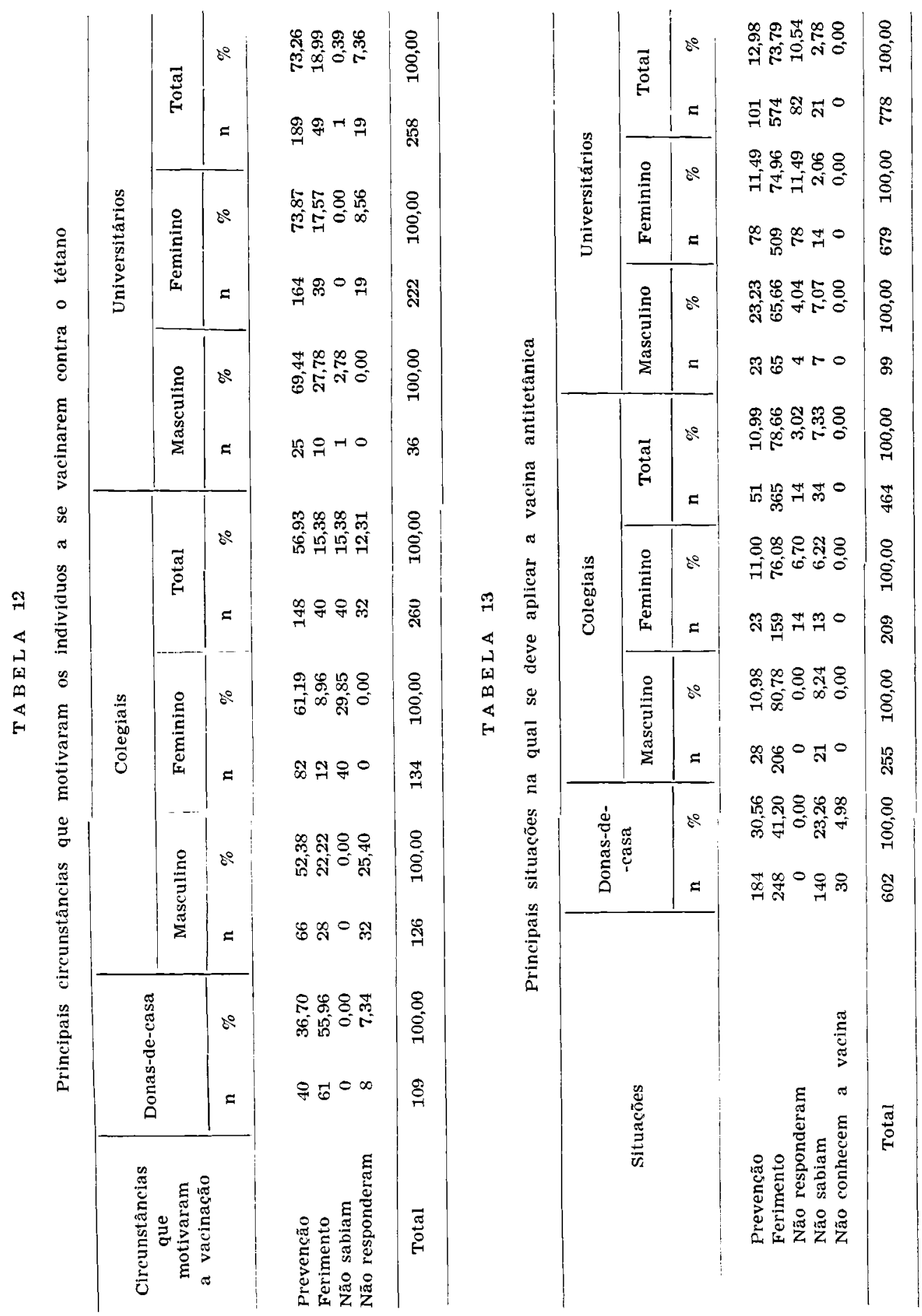


BALDY, J. L. da S. et al. - Tétano e vacinação antitetânica: estudo na população urbana de Londrina (PR), Brasil. Rev. Saúde públ., S. Paulo, 10:151-66, 1976.

vadíssima percentagem de $73,79 \%$ entre os universitários (Tabela 13). Grande párte, pois, da população estudada não considerava a vacinação antitetânica recurso profilático, mas terapêutico, a ser utilizado nas emergências.

Verificou-se também a ocorrência de freqüente confusão (desconhecimento ou inexistência de diferença) entre vacina e suro antitetânicos (Tabela 15), em todos us grupos.

Esses fatos devem constituir advertência incisiva quanto à conduta médica a ser estabelecida em casos de ferimentos graves, em relação aos quais a não aplicação do soro antitetânico ou da imunoglobulina humana antitetânica ${ }^{1,12}$ está eventualmente condicionada às informações fornecidas pelo doente ou pelo acompanhante; os dados relativos à imunização prévia, com observância dos esquemas padronizados ${ }^{1}$, devem ser avaliados, nessas oportunidades, com muita cautela e submetidos a cuidadosa crítica do perquiridor.

Quanto ao conhecimento dos locais onde a vacina antitetânica pode ser encontrada, 32,55\% das donas-de-casa, $10,99 \%$ dos colegiais e $8,10 \%$ dos universitários desconheciam onde obter esse agente imunizante (Tabela 16). E de causar preocupação que quase um terço das mães de família - as responsáveis habituais pela providência de vacinar as crianças - da área urbana de Londrina descouheçam esse fato, sobretudo quando nesse município o toxóide tetânico se acha disponível gratuitamente no Posto de Suúde do $17 .^{\circ}$ Distrito Sanitário do Estado do Paraná e, a preço relativamente baixo, em qualquer farmácia.

Para confirmar, à saciedade, a predominância de concepções errôneas a respeito da prevenção do tétano, $31,23 \%$ das donas-de-casa, $10,56 \%$ dos colegiais e $5.14 \%$ dos universitários entrevistados ('Tabela 17) admitiram a absurda possi- b.lidade de que o uso de fumo, urina, e.terco e teias de aranha evitam a instalação da doença.

\section{CONCLUSOES}

Conclui-se, pois, que conceitos e noções incorretos e carência de informação quanto ao tétano, à vacina antitetânica e a Jutras medidas para sua prevenção prevalecem na população da zona urbana de Londrina, representada por donas-de-casa, colegiais e universitários.

Esse fato torna-se mais grave na medida em que as donas-de-casa constituem em nossa organização social o responsável pela providência de medidas profiláticas quanto às doenças prevalentes na infância, entre as quais o tétano se agrupa. Por outro lado, a falta de informação dos universitários, em relação à doença e à vacina antitetânica, em proporção significativamente alta, constitui evidência do que se verifica a esse respeito em grupos da população considerados "de nível cultural elevado", em nossa sociedade.

Pode-se, portanto, deduzir que o problema deva agravar-se, em nosso meio, nas populações da zona rural, de que é muito baixo o índice de informação sanitária e pequena a possibilidade de acesso aos recursos profiláticos, apenas disponíveis na área urbana dos municípios.

A alta prevalência do tétano no Norte do Paraná, ilustrada pelo número relativamente grande de casos internados no Hospital Universitário de Londrina, no período de 1972 a 1975, está em concordância com os dados obtidos em nosso estudo, confirmando o desconhecimento predominante na população desse município quanto a uma doença grave, de tratamento dispendioso, com ainda elevado indice de letalidade, para cujo controle se dispóe, gratuitamente ou a baixo custo, de agente imunizante inócuo e soberbamente eficaz. 
BALDY, J. L. da S. et al. - Tétano e vacinação antitetânica: estude na população urbana de Londrina (PR), Brasil. Rev. Saúde públ., S. Paulo, 10:151-66, 1976.

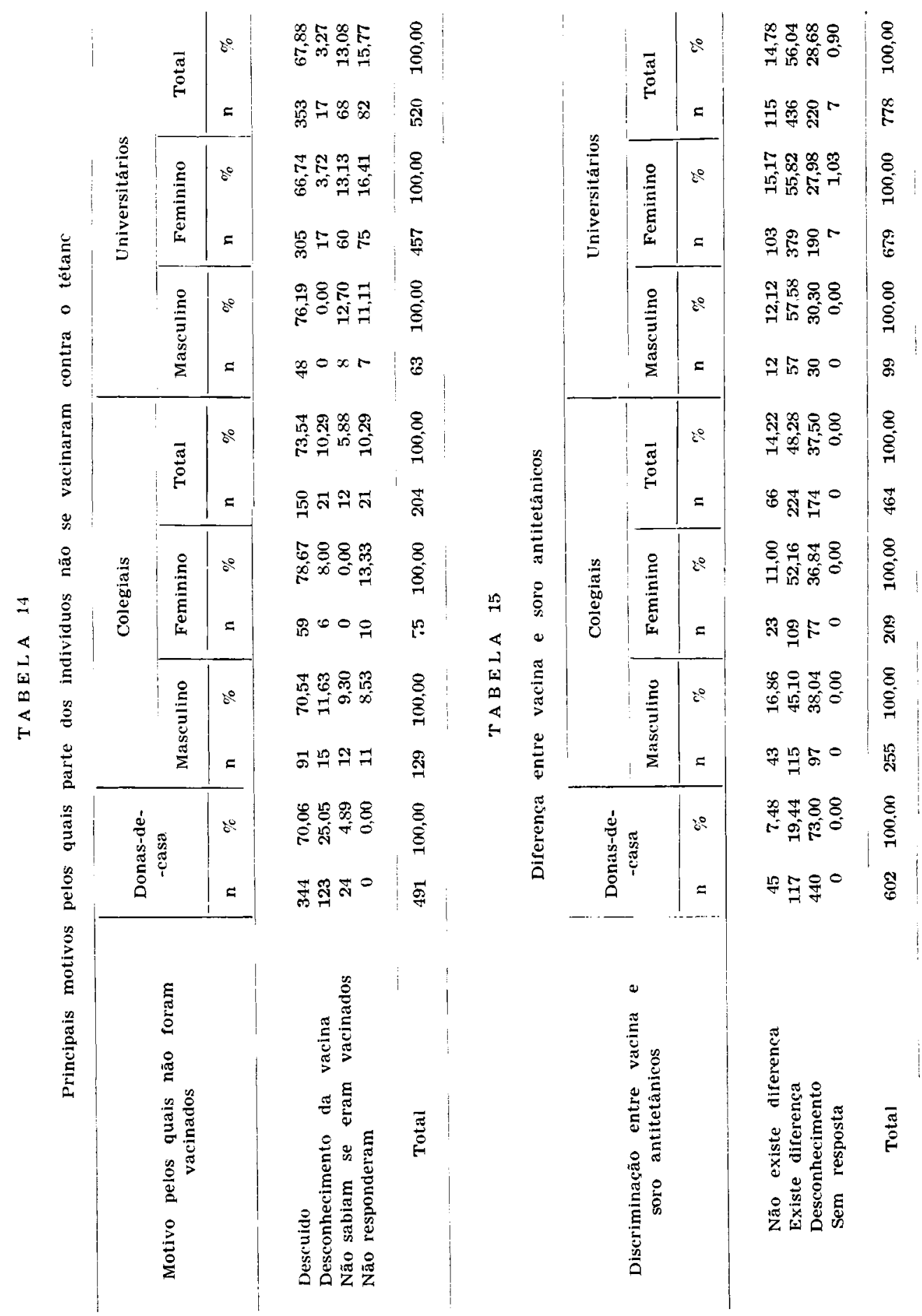


BALDY, J. L. da S. et al. - Tétano e vacinação antitetânica: estudo na população urbana de Londrina (PR), Brasil. Rev. Saúde públ., S. Paulo, 10:151-66, 1976.

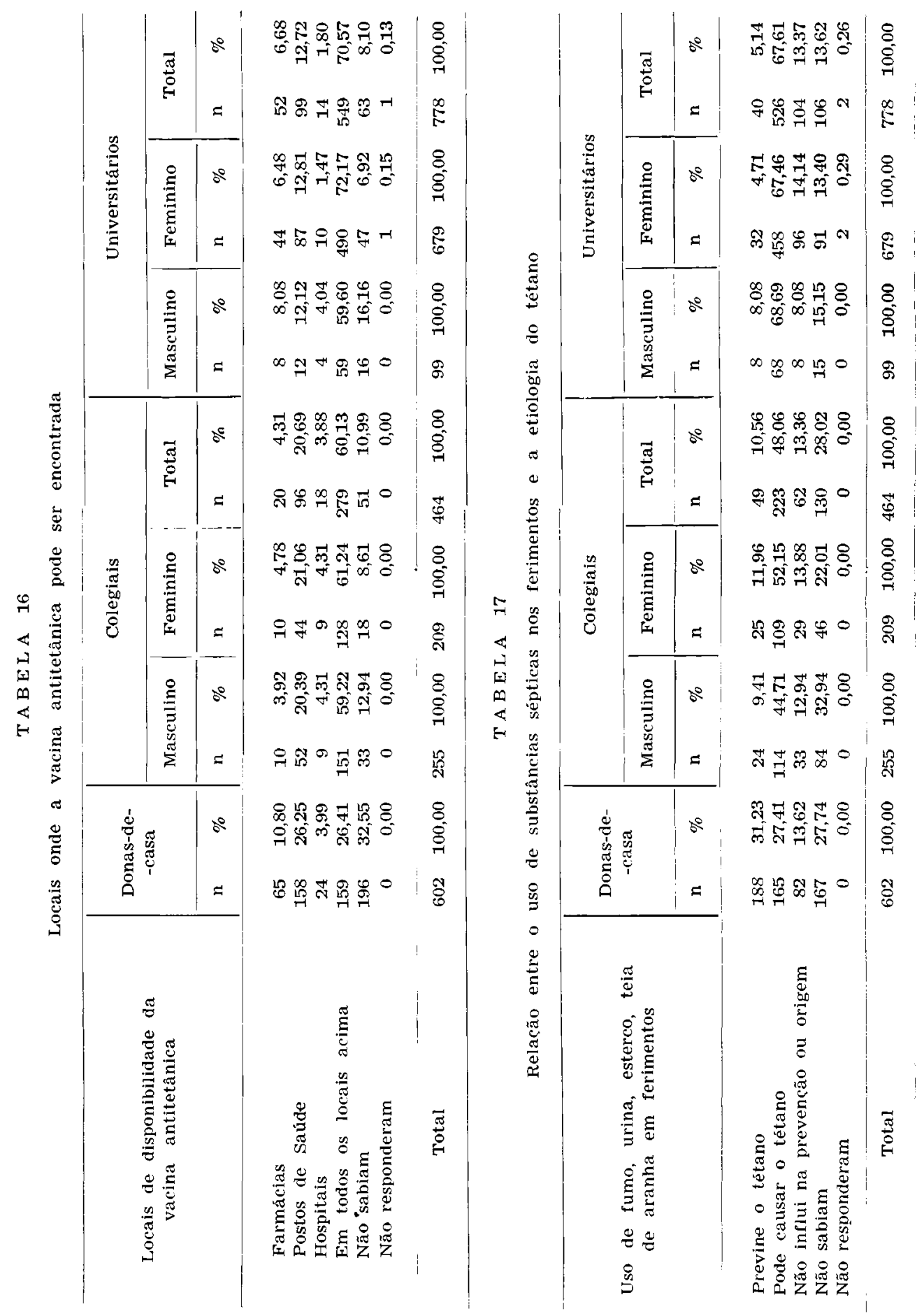


BALDY, J. L. da S. et al. - Tétano e vacinação antitetânica: estudo na populasão urbana de Londrina (PR), Brasil. Rev. Saíde pübl., S. Paulo, 10:151-66, 1976

A vacinação antitetânica obrigatória de grupos profissionais mais expostos, das gestantes e dos escolares ${ }^{11}$ permitiria por certo reduzir acentuadamente a incidência do tétano, doença que, ao lado de outras facilmente preveníveis - tais como poliomielite. sarampo e difteria --. constitui ainda sério problema de saúde pública no Brasil.

Em nosso país. nas escolas de primeiro grau. segundo grall e superiores. as matrículas não são permitidas sem apresentar-se comprovante de vacinação antivariólica. Parece-nos contrasenso que, para uma virose sob controle. desde 1971, no Brasil " essa exigência seja tão rigorosa. enquanto em relação à racina anti- tetânica - capaz de prevenir com absoluta segurança uma doença que mata 13.000 brasileiros por ano ${ }^{2}$ — seja tão frouxa e incidental a preocupação dos legisladores da Medicina Preventiva em torná-la obrigatória. pelo menos para alguns grupos selecionados da população.

Os resultados obtidos em inquéritos semelhantes ao que realizamos exigem reflexão e rigorosa auto-crítica das autoridades responsáveis pelos programas de educação sanitária em nosso país. Os recursos públicos destinados à saúde não derem ser despendidos em propagandas onerosas. cuja linguagem nada tem a ver com o nível cultural e a capacidade de compreensão do nosso povo.

RSPU-B/309

BALDy, J. L. DA S. et al. - [Tetanus and antitetanic vaccination: a study in the urban population of Londrind (Paraná, Brazil)]. Rev. Saude públ., S. Paulo, 10:151-66, 1976.

Summary: Employing a standardized questionary. an inquiry uas made among three groups in the urban jopulation of the city of Londma Parana. Brazil), including 602 housewues, 464 high-school and irs unuersity students. The aims were: to determine the number of sibjects vaccinated against tetanus; to evaluate the degree of knouledge regarding tetanus, antitetanic vaccine and antitetanic serum; to establish a relationship between these indices and some characteristics of each group of the population studied. The conclusions pointed to incorrect concepts and lach of information about tetanus and antitetanc vaccme being prevalent among the population of the urban zone of Londrina. The signification and the consequences of these facts are discussed, and it is assured that the high morbidity of tetanus, in Brazl. should mean a serious warning to Public Health authorities. These and similar results should be regarded when changes in programmes of antitetanic aracination are considered; these results are applicable to revieus on methods of health education regarding this subject, as well as scientificale resourccs arailable for its prophilaxis.

Uniterus: Tetanus. Antitetanic vaccine. Antitetam serum. Urban population, Londrina (Brazil).

\section{REFERENCIAS BIBLIOGRÁFICAS}

1. amato Neto. v. et al. - Imunizasóes. São Paulo, Sarver, 1971.

2. BYTCHENKO, B - Tetanus as a world problem. In: INTERNATIONAL CONFERENCE ON TETANLS. 2 ${ }^{\mathrm{m}}$,
Bern, 1966 Proceedugs. Bern, Hans Hubers, 1967.

3. FISCHER, R, A, \& YATES, F - Tábua de numeros ao acaso In: Tabelas estatistecas para blotogra. medicma 
BALDY, J. L. da S. et al. - Tétano e vacinaşāo antitetânica: estudo na populą̧ão urbana de Londrina (PR), Brasil. Rev. Saúde públ., S. Paulo, 10:151-66, 1976.

e agricultura. São Paulo, Ed. Univ. S. Paulo, 1971

4. KOIFMAN, S. et aI. - Tendências epidemiológicas do tétano registrado na Guanabara, 1960-1969. Rev. Soc. bras. Med. trop., 8:15-26, 1974.

5. LACAZ, C. S. et al. - Introducão à geografia médica do Brasil. São Paulo, Edgard Blücher/Ed .USP, 1972.

6. LACAZ, C. S. - o problema do tétano no Brasil. Rev. Ass. méd. bras., 12: 33-41, 1966

7. LoPEZ, M. et al. - Tratamiento intensivo del tétanos clínico. Bol. Ofic. sanit. panamer., 78:138-47, 1975.

8. RAINERI, H. C. et al. - Treatment of tetanus at "Hospital das Clinicas". School of Medicine, University of São Paulo. Rev. Inst. Med. trop. S. Paulo, 13:418-21, 1971.

9. TAVARES, W. - o Clostridium tetani e o tétano. Rev. Soc. bras. Med. trop., 7:57-68, 1973.
10. TONELLI, E. et al. - Doenças infectuosas de maior letalidade no Hospital Carlos Chagas da Faculdade de Medicina da U.F.M.G. Rev. Ass. med. Minas Gerals, 20:137-49, 1969.

11. VERONESI, R. - Controle do tétano no Estado de São Paulo. Análise e comentários em torno dos resultados obtidos da vacinação compulsória dos escolares. Rev. Hosp. Clin. Fac. Med. S. Paulo, 26:223-8, 1971.

12. VERONESI, R. - Tétano. In: VERONESI, R., ed. - Doenças infecciosas $e$ parasitárias. $4 . \mathrm{a}$ ed. Rio de Janeiro, Guanabara-Koogan, 1969. p. 496-532.

13. VERONESI, R. - Tétano: grave problema de saúde pública no Brasil. Rev. paul. Med., 52:456-60, 1958.

14. VERONESI, R. - Tétano e sarampo: quanto custam no Brasil? Clin. Geral, $7(5): 24-38,1973$.

Recebido para publicação em 05/11/1975 A provado para publicacão em 05/01/1976 